\title{
GSM and the Nigerian Economy: The Journey from 2004 to 2019
}

\author{
Michael A. Enahoro ${ }^{1} \&$ David B. Olawade ${ }^{2}$ \\ ${ }^{1}$ Department of Business Administration, Swiss Management Center University, Switzerland \\ ${ }^{2}$ Department of Environmental Sciences, University of Ibadan, Oyo State, Nigeria \\ Correspondence: David B. Olawade, Department of Environmental Sciences, University of Ibadan, Oyo State, \\ Nigeria. E-mail: olawadedavid@gmail.com
}

Received: February 12, 2021

doi:10.5539/ijef.v13n7p69
Accepted: May 2, 2021

Online Published: June 12, 2021

URL: https://doi.org/10.5539/ijef.v13n7p69

\begin{abstract}
The turn of the $21^{\text {st }}$ century saw Nigeria liberalize its telecommunications sector with the deregulation of the industry, and the introduction of the Global System for Mobile communications (GSM) network platforms in the country. This move had an immediate positive socio-economic impact. Sectors like information technology, banking and finance, online trade, sporting, education, entertainment, security, and healthcare have significantly improved over the years. So far, tens of millions of direct employments have been directly provided via the platform. Furthermore, the country's GDP attributable to telecommunication has constantly increased since the deregulation of the telecommunication industry. The paradigm shift has since seen the industry grow at a pace faster than most established networks in the world. However, several demerits have also stemmed from this advancement such as cyber-crime, cyber-bullying, blackmailing, and reduced productivity attributed to social media distractions. Even with the apparent progress, it can be concluded that the telecommunication sector is still quite underexploited in Nigeria. The lack of basic infrastructures like constant electricity and accessible road networks across several parts of the country, and the harsh economic policies have severely limited the potential for heightened economic productivity.
\end{abstract}

Keywords: Global System for Mobile communications (GSM), telecommunications, Nigeria, economy, GDP

\section{Introduction}

Consequently, it is known that telecommunications services in Nigeria started in 1856 by Cable and Wireless submarine cable project, connecting Lagos to London. By 1914, Nigeria already had a telecommunications network linking the north and the south of the country by wire services, predominantly via telegrams and a few telephones owned by the elites and British colonial administrators, who had to establish communication services with their home government in London, England (Ige, 2012). Nkordeh et al. (2017) further outlined that, between 1960 (year of independence) to 1999, Nigeria saw an improvement in investments in telecommunications but with heavy restrictions on utilization, and widespread ownership of telephones and telecommunications services. This was because the Military Era leadership censored and highly restricted the industry and its growth. Telephones were mostly restricted to offices, and the homes of elite Nigerians, Embassies, Military formations, big businesses like hotels, supermarkets, hospitals, universities, and a few other places of interest to the Military leadership. Between 1960 and 1990, there were only 114,000 telephone connections made available via the Nigerian Telecommunications Limited, the government-owned sole supplier of telecommunications services. At that point, it was clear that the presentation of telephone utilities in the nation was not propelled by monetary or business thought processes. It was not intended to improve monetary development. It was initially evolved as a device for control and oppression (Adediran et al., 2017).

Ndukwe (2011) provided a further detailed historical perspective in that as at independence in 1960, with a populace of around 45 million individuals, the nation just had around 18,724 telephone lines for usage. This meant a teledensity of about 0.5 phone lines per 1000 individuals. The phone network comprised of 121 trades of which 116 were of the manual (magneto) type and just 5 were automated. Between independence in 1960 and 1985, telecoms administrations became commercialized in Nigeria. The old department of Post and Telecommunications ( $\mathrm{P}$ and $\mathrm{T}$ ) under the Ministry of Communications got separated and Nigeria External Telecommunications Limited (N.E.T) was made to deal with outside telecoms administrations while the old P and $\mathrm{T}$ took care of the inner organization.

By January 1985, the recent Post and Telecommunications division was merged with NET to frame Nigeria 
Telecommunications Limited (NITEL), a government-owned Limited Liability Company (Micah, 2017). Notwithstanding the enormous interests in the media communications industry during the military years (38 years), almost no advancement and development were seen in the business (Bakare et al., 2017). The return of a democratic government in 1999 brought a fully liberated telecommunications sector, this introduced the procurement of 3 GSM licenses in January 2001 for $\$ 285$ million each and further held a permit for NITEL. Eventually, just 2 out of 3 organizations at auction; MTN communications and ECONET wireless, and NITEL were granted full GSM licenses. Over the years, Nigeria's broadcast telecommunications sector advanced to eventually get one of the quickest developing sectors and this is because of the government's progression strategy of the sector in 2000 (Adediran et al., 2017).

Ndukwe (2011) outlined that the liberation of the telecommunication sector resorted to a paradigm shift in the economy of Nigeria. By 2004, the initial 400 thousand lines under NITEL, had exponentially grown to become 14 million. The impact was revealed by the telecoms industry's contribution to the Nigerian National Gross Domestic Products (GDP)- 3.66\% for 2009, 6.2\% for 2010, and 9.53\% for 2018. Also, there were well over 110 million connections, with a $48.3 \%$ internet penetration, and over 3 million job direct and indirect job opportunities were created for young Nigerians (Aminu \& Rafiu, 2019). Even with the positive effect, Asogwa et al. (2013) posited that the effect of the Nigerian media communications upheaval on the Nigerian economy has not been completely valued, which is broadly due to the monumental infrastructural challenges operators still face, high logistics costs, inconsistent power supply, high technical staff depth, multiple taxations, high-interest rates, lack of credit structure, low Tech SME platforms and entrepreneurs, conflicting government policies and lack of adequate youth tech start-ups.

However, the implication of such massive development on the nation's economy is an aspect that most empirical studies are yet to fully place adequate emphasis on. There are few holistic studies to critically examine the multidimensional impacts of GSM in Nigeria. Many studies that have been carried out on the influence of GSM halted in 2011 and 2016 without a comprehensive analysis of the socio-economic aspects of its impact. It is against this background that this study investigates the socio-economic effect of GSM evolution on the Nigerian economy given the critical integration of telecommunications services on Nigerians, especially from the commencement of operational network activities in 2004 until 2019. This study integrated the policy of relevance by providing an up-to-date account. It also highlights the multi-layered impacts of GSM penetration in Nigeria.

\subsection{Study's Methodology}

This narrative review utilized secondary data sources consisting of over 20 journal articles about telecommunication and the digital economy in Nigeria, reports from the Nigerian Communications Commission, the United Nations Conference on Trade and Development, and GSMA Intelligence. Articles from Nigerian dailies like; The Guardian, and The Star were also employed for the review.

\section{Literature Review}

\subsection{History of the Global System for Mobile Communication (GSM) Platform}

GSM (Global System for Mobile Communications) is a computerized versatile communication framework that is broadly utilized in Europe and different parts of the world. The invention and improvement of telecommunications in the world started during the 1830s (Micah, 2014). Sir Charles Wheatstone and Sir William Fothergill Cooke developed the first commercial electrical telegraphy (Ajayi, 2008). GSM utilizes a variety of Time Division Multiple Access (TDMA), which is the most generally utilized of the three computerized remote communication advances (TDMA, GSM, and CDMA). GSM digitalizes and compresses data, at that point sends it down a channel with two different streams of user data, each in its time slot. It works at either the $900 \mathrm{MHz}$ or $1800 \mathrm{MHz}$ frequency band (ITU, 2011). Mobile services dependent on GSM innovation were first launched in Finland in 1991, there were not so many mobile networks in the world at the outset yet with the fast spread of GSM, it would address over 98.4 percent of all worldwide mobile connections by 2018 (NCC, 2012).

The improvement of GSM in the world was provoked by the need to give consistent media communications through Europe. Analog mobile telephony extended dramatically back in the mid-1980s and operators discovered it progressively hard to interconnect with different European networks (Ajiboye et al., 2017). To address this concern, an investigation group called 'Gathering Special Mobile' (where GSM got its name) was initiated and was entrusted to give a standardized framework to mobile telecommunication. Out of this team (and after seven years), the GSM standard was figured out. In January 1992, the first GSM network, OY Radioing AB in Finland went on air (Sormunen \& Antilla, 2011). Mobile services dependent on GSM innovation were first 
dispatched in Finland in 1991. Today, the quantity of worldwide users of GSM is as of now around 5 billion and is anticipated to develop to 5.86 at least billion by 2025 (Statista, 2020).

Table 1. Unique mobile subscribers by global region

\begin{tabular}{lccc}
\hline Region & Unique mobile subscribers (millions) \% & of global subscriber base Subscriber penetration (\% of population) \\
\hline Asia Pacific & 2,765 & $55 \%$ & $68 \%$ \\
- China & 1,081 & $21 \%$ & $78 \%$ \\
- India & 730 & $14 \%$ & $54 \%$ \\
Europe & 465 & $9 \%$ & $86 \%$ \\
Latin America & 459 & $9 \%$ & $71 \%$ \\
Sub-Sahara Africa & 436 & $9 \%$ & $44 \%$ \\
Middle East \& North Africa & 391 & $8 \%$ & $63 \%$ \\
North America & 292 & $6 \%$ & $80 \%$ \\
CIS & 227 & $5 \%$ & $79 \%$ \\
TOTAL: & $\mathbf{5 , 0 3 5}$ & $\mathbf{1 0 0 \%}$ & $\mathbf{6 7 \%}$ \\
\hline
\end{tabular}

Source: GSMA, 2015.

\subsection{GSM Evolution in Nigeria}

The Nigerian Communication Commission Decree (NCCD) 75 was declared in 1992 and turned into the fundamental enactment overseeing the telecoms industry (Oyejide \& Bankole, 2001). The decree changed different parts of telecommunications activities including the installation of terminals or other gadgets; provision and activity of private network links that utilized cables, radio communication or satellite solely within Nigeria; availability and activity of public mobile communication (GSM standard); provision of community telephones; provision and activity of value-added network services; repair and maintenance of telecommunications facilities; and cabling (Akinyomi \& Tasie, 2015).

The establishment of NCC prompted the issuance of licenses for these private telecommunications operators. These incorporate fixed telephone service providers that have enacted 90,000 lines, 35 Internet service providers with a customer base of around 17,000. The return of democracy in 1999 achieved a total liberation of the telecommunications sector, by auctioning 3 GSM licenses in January 2001 for $\$ 285$ million each and saving a license for NTEL (Bakare et al., 2017). Nigeria's first GSM innovation was launch in May 2001, when South Africa's MTN set up its Nigerian subsidiary, MTN Nigeria. In August that year, Econet, presently Airtel, likewise launched its Nigerian subsidiary. Globacom Nigeria entered the market in August 2003, to be joined by Etisalat (presently 9mobile), in October 2008. MTN Nigeria is the largest mobile operator in the country as far as the number of users, with a market share of $40 \%$ as of August 2018, trailed by Globacom and Airtel at 25\% each, and 9mobile at 10\% (Oxford Business Group, 2020).

In the previous few years, mobile penetration has risen pointedly, with the NCC reporting an all-outnumber of telephone connections which escalated from 101.8 million in May 2012 to 148.9 million in May 2016. Total telephone connections fell after the NCC moved to uphold guidelines commanding SIM card registration, with the commission putting the figure 139.4 million in August 2017. Notwithstanding, this was trailed by a $15.4 \%$ rise through to August 2018, when total connections hit 160.9 million (Oxford Business Group, 2020).

Statista (2019) confirmed the submission of OBG with a forecast that the conceivable development of GSM penetration would grow above of 140 million by 2025. This infers that the telephone penetration rate is about $85.3 \%$. As indicated by the commission, GSM technology held the largest market share as of August 2018 with 99.7\%, followed by CDMA associations, fixed wireless and wired associations, and voice over internet protocol (VoIP) services, which each held a market share of $0.1 \%$.

Imported Nokia telephones were at first the leading mobile devices in Nigeria, even though there were other supporting brands like Samsung, Sagem, Motorola, Semen, Bird, Sony Ericsson etcetera. Blackberry, and HTC as well as Chinese brands like Tecno, Infinix, are also common. While none of the major global device manufacturers have assembly plants in Nigeria, cell phones have become an essential item to numerous entrepreneurs in Nigeria (Wojuade, 2005). Nigeria's tech sector is an outgrowth of the Global Systems for Mobile Communications (GSM), which was introduced in Nigeria in August 2001, a couple of months after the creation of the National Information Technology Development Agency. About two decades later, more than 100 million individuals have access to mobile telephones and internet use rose to nearly 50\% (Internet World Stats, 2019).

\subsection{GSM Penetration Journey in Nigeria from 2004 to 2019}

The Telecommunications sector in Nigeria has significantly improved from a government monopoly organization with around $11,400,000$ subscribers in 2004 to over 180,250,000 subscribers in 2019. The 
teledensity followed the same growth pattern, from $12 \%$ in 2004 to over $100 \%$ in 2019 internet penetration grew from $8 \%$ to $44.68 \%$ in 2019 and with the sector contributing over $\$ 70$ billion to GDP at just 9\% (from 2004-2019). It shows that mobile internet connectivity in the nation rose to contain more than 92 million people, and rose to get one of the fastest-growing telecoms markets in Africa and the world (Nkordeh et al., 2017).

Bakare et al. (2017) posited that the Telecommunications sector has pulled in around 25 billion US dollars from direct foreign investment into the country while as far as job opportunity, an absolute number of 1,135,000 employments were made. The industry has developed to such an extent that it helps the development of service sectors like insurance, IT, banking, consultancies, transportation, Small and Medium Scale Enterprises (SMEs). There has also been a critical improvement in the activity of the economy (Azubike \& Obiefuna, 2014).

Increased yearnings of the population to communicate and bridge the urban-rural divide, given that opportunities are created in the service industry, rapid digitalization of records, and service delivery has been key to the shift in the socio-economic paradigm that has become evident. Nwakanma et al. (2012) ascribed Nigeria's Telecommunications revolution and rapid growth to the activities of the 2001 Liberalization efforts and eventual privatization exercise. It was further outlined that from 2004, on commencement of operations of GSM networks in Nigeria, steady growth and enhanced opportunities have become integrated across various sectors in the country. Gold (2011) highlighted that more key benefits of the telecommunication revolution are required, as the online marketplace is still in its developmental stages given the direct influence on GDP and other economic indices, with the high youth and graduate unemployment currently experienced in Nigeria.

Ndukwe (2011) clearly aligns and outlined the difference from the military era of restricted communications to the post-liberalization period, under review (2004-2019) by showing the growth of subscriber and service development over the same period, and opined on the areas served by alignment of the industry's FDIs' into areas wherein opportunities for Nigerian SMEs were created, leveraged and translated into a significant increase in job creation and online business platforms.

Aigbinode (2016) asserted that the present Telecoms sector revolution has transformed Nigerian society in different ways since the dawn of the new millennium. Nonetheless, as promising as the telecommunications industry in Nigeria might seem, there is a need to do a holistic comparative study to examine the socio-economic impact of GSM penetration in Nigeria. This study highlighted how the revolution in the telecommunications industry has changed the lives of Nigerians. In consonance to Mould (2019), this research work investigated if truly the telecommunications industry has been a significant contributor to the economy, how it has enhanced the lifestyle of Nigerians, businesses, social engagements, and networks, and the commensurate reflection on GDP, considering the rate of unemployment in the nation and untold hardship that many Nigerians continue to complain about. In furtherance to the above-mentioned challenges, it is important to recognize that Nigeria's GDP in the period under review, and the infusion of its importance in consonance to the teledensity and spread of the GSM network across the country, has delivered some opportunities for tackling youth and graduate unemployment, development of online business opportunities, digital banking and services provisions with eand m-commerce (Chidozie et al., 2015).

\subsection{GSM Penetration and Economic Opportunities}

Active internet subscription (GSM) between 2014 and February 2015 was more than 80 million, from an active subscriber statistic of more than 145 million. In more clear terms, internet penetration was enhanced by the circulation of GSM; and the result of this is monstrous, it implies the infiltration of GSM may be decidedly affecting the socio-economic fabric of the country (NCC, 2017). Around 19 years after GSM penetrated Nigeria, E-commerce is by all accounts the new market by which jobless graduates make money and even use their inventive cap. Not just has the Nigerian socio-economic framework changed, however, expertise is likewise now being traded; Nigerians are progressively being viewed as expatriates in other countries. This is a clear differentiation to when the country was reliant exclusively on oil for more than 40 years and which the effect on the socio-economic life of the people was restricted (Guardian, 2019).

Nigeria's tech sector is an outgrowth of the Global Systems for Mobile Communications (GSM), which was introduced in Nigeria in August 2001, a couple of months after the creation of the National Information Technology Development Agency (NITDA). About two decades later, more than 100 million individuals have access to mobile telephones and internet use has risen to around 50\% (Internet World Stats, 2019). One of the most apparent is the opportunities that GSM has opened for Small-medium scale enterprises. Before the advent of GSM, only Multinational and large-scale businesses could afford to subscribe to marketing and business promotion because the traditional media platforms were the only way by which people marketed (Aminu \& Rafiu, 2019). 
However, now GSM has made social media and the internet very accessible to people. Therefore, business proprietors can promote their businesses, regardless of the scale on social media. Small scale businesses now subscribe to product photography, content description, and videos to market their businesses on social media platforms like Facebook, Instagram, Twitter, Google Search Engine, YouTube, and many more (Unctad, 2017). Most SMEs in Nigeria utilize the Global System of Mobile communication (GSM) to speak with their customers and by this form a more grounded relationship. They have understood that easy access to GSM and the conveyance of their products or services are significant drivers in creating and sustaining market competitiveness nationally and globally (Durndell \& Haag, 2002).

The usage of mobile phones over a few years in business has had a significant positive effect on monthly turnover. Using the internet and mobile phones to interact with customers and to obtain information about the market has had a remarkable positive impact on business turnover. Business owners who are utilizing the developments in the telecommunications industry have significantly higher turnover than those who are not leveraging such developments (Urama \& Oduh, 2012). It is further intriguing to note that organizations in Nigeria are progressively utilizing mobile applications, websites and SMS, social media ads, and numerous different ways to publicize to various individuals across the world. In 2013, Nigeria was the thirteenth biggest generator of mobile advertisement impressions worldwide. This growing mobile advertising has been upheld by the presence of many local mobile advertising platforms.

The digital inclusion that the penetration of GSM has made has created new vocations, new business ideas for Nigerians. Nigerian retailers are progressively utilizing the internet to drive sales. As early as 2013 to 2014, online transactions increased by $15 \%$, and $60 \%$ as online buyers use their mobile phones to complete the purchases. Nigeria's e-commerce market pulled in \$200 million in foreign investment as of 2014 and created 12,000 job opportunities between 2012 and 2014. The figure has heightened since then and e-commerce has changed the essence of business in Nigeria (Aigbinode, 2016).

Different service providers and traders have made social media their marketplace. People sell and purchase clothes, food, electronics, toiletries, wedding items, and many more on social media. People hire service providers like graphics designers, babysitters, virtual assistants, writers, dispatch riders, and many other service providers on social media. Currently, there are applications for practically anything, for job search, online courses, shopping, cooking, makeover, and Do-It-Yourself ideas. These applications and the avalanche of contents on the internet have inspired many youths to become entrepreneurs just by owning an Android or iOS mobile phone (Aminu \& Rafiu, 2019). Also, tech firms have grown exponentially over the last decade. In 2012, two Harvard Business School graduates co-founded Jumia, a Nigerian e-commerce website and one of the first tech companies in the country. From that point forward, tech firms have been set up in the fields of energy, agriculture, banking, transportation, logistics, health, and finance.

Generally, there is a trade of cash, and regularly the creation of some type of pleasure. Somewhat, this happens in the "large" aggregator organizations that make available technology and platforms, yet additionally in the "individual organizations" that they empower (for example, individuals leasing their actual resources or selling their experience on request). For instance, Asuqu connects small businesses to creative people and professionals that offer a needed service, such as photographers, animators, short film creators, creative directors, web designers, architects, engineers, consultants, make-up artists, and interior designers (Suominen, 2017).

These digital platforms are frequently assessed through mobile applications which unite total demand and supply in manners that were beforehand unthinkable. Now, it is quicker, less expensive, and all the more effectively organized, including geographic zones/service sectors where lower density would in general make this more confounded. They are subsequently setting up new business opportunities. Exchange and search costs, just as friction, are diminished by connecting those contributing assets or services to those wishing to consume them. These platforms are adequately new "commercial centers" that quickly match supply and demand on a large scale, both for location-bound work (for example; Uber, TaskRabbit) and online location, independent work like; Upwork or Amazon Mechanic tasks (Ibukan \& Ackerman, 2019).

\subsection{GSM Penetration and Digital/Mobile Payment Systems}

Different banks in Nigeria have their Mobile Apps by which customers can conveniently carry out transactions of about 50 million or more according to individual bank policies. Also, customers with the upgraded version of mobile phones also known as Android and IOS can simply use their bank-generated transfer code to implement transactions successfully. The status quo has reduced the rate of armed robbery drastically as people hardly move with large sums of cash, neither do they keep huge sums at home (Jackson, 2017). Although, Micah (2017) argued that the current state of things may have drastically increased Cyber Crimes. In any case, the rise of GSM 
has achieved a stupendous improvement in the significant area of the economy, like banking, telecoms, and commerce in general. GSM is perhaps the most massive improvement at any point to have occurred in the telecommunications industry (Wojuade, 2005). The penetration of GSM has brought numerous profits which incorporates expanded financial sector turnover through loans, advances, progresses, e-commerce, e-banking (Iwayemi, 2017).

The uptake of debit and credit cards just as innovative online, and mobile payment options has grown over the years. In 2014, credit and debit cards represented the greater part of all online business transactions in esteem terms. In any case, their share is anticipated to drop to 46 percent by 2019 , as e-wallets and other alternative payment platforms (like mobile money) acquire prominence (WorldPay, 2015). Strangely, WorldPay expectations emerged as E-wallets seem, by all accounts, to be especially preferred as a platform for payment for international transactions. The 2016 study of cross-country internet business customers across 26 nations found that e-wallets (like PayPal) were the preferred option for $41 \%$ of respondents, trailed by credit cards (33\%), and debit cards/bank transfer (18\%) (International Post Corporation, 2017). Thusly, the infiltration of GSM has taken into account more cross-bounder transactions including small-scale importation by normal Nigerians (Bakare et al., 2017).

Additionally, electronic banking like Automated Teller Machine (ATM), services, online monetary exchanges, international credit uptake of debit and credit cards and debit card facilities, airline ticketing, and reservations are a portion of the various ways that the introduction of GSM in the telecommunications industry has helped the improvement, refinement, security and fast transactions in the Nigerian financial sector (NCC, 2017). Nigeria is as of now positioned as the biggest and quickest developing telecommunications market in Africa, and among the 10 fastest growing telecommunications markets in the world, a sign of its heartiness and great profits on investment (Anioke, 2011).

\subsection{GSM Penetration on Social Relationships and Networking}

Social and family relationship alongside the security circumstance of Nigeria has likewise been essentially improved (Ajiboye et al., 2007). GSM is utilized by Nigerians generally to communicate with another. Ajiboye et al. (2007) clarified that students utilized it to communicate with their course mates, companions, lecturers, and family members. Furthermore, family matters, finance, and academic matters constitute the major functions of mobile communication for most people. Prior to the existence of GSM, these functions had been fulfilled manually, yet the accessibility of mobile phones has restricted the majority of the students' travel, followed by facilitation of exchange information whenever the need emerged (Adomi, 2006).

In addition, youths can explore opportunities on social media due to their easy access to smartphones. Different skits, videos, and contents are flying all over social media and these youths generate money from the recognition they get from those contents. For instance, in the entertainment industry, music artists release songs and videos which they sell to different websites for sizeable sums, and these websites in turn make their money by the deluge of people who visits their websites for download or to stream. The same thing applies to the movie industry. This development has brought huge improvement to the challenge of piracy and has heightened the revenue generated in the entertainment industry (Mould, 2019).

\section{Conclusion}

The conclusion in this finding dwells on the significance of the study. This study discovered that the penetration and circulation of GSM and the evolution of the telecoms industry have influenced key economic and social paradigm shifts in the Nation. Although, it would be an erroneous submission to say that every contribution of GSM penetration is positive or that GSM is the only and major catalyst to the economy. However, the argument is clarified; thus, the penetration of GSM has reduced exorbitant rates of subscriptions and communication that was deployed during the existence of NITEL. From 2001, the deregulation of telecommunications ushered in an unprecedented change in the landscape of Nigeria; an evolution that became much more apparent in 2004. The penetration of GSM technology and freehand given to Network providers that are operating gave rise to wide accessibility both in Urban and Rural Areas and reduced the digital divide drastically. Just like Micah (2017) opined, NCC continued the regulation of the sector to check and balance irregularities apparent in the market. As a result, access to and utilization of GSM technology has soared among a population of users across locations, occupations, and classes.

Based on the foregoing, there have been foreign direct investments attractions, a remarkable contribution to the GDP, creation of over 2.5 million direct and indirect jobs, innovations, and inventions of witty and novel business ventures, ease of doing businesses, consumer surplus, and elevation of social interactions. Although, Anioke (2011) stated that there have been negative inclinations like cyber-bullying, cybercrimes, social media 
distractions, hidden charges by telecoms operators, and reduction in cultural values, based on collected evidence, but the positive impact of GSM penetration far outweighs the negative consequences. Therefore, along these lines, it could be concluded dependent on the empirical finding, filed-proof, and the contextual investigation approach adopted in this study, that the GSM penetration in Nigeria has had a synergistic impact on the socio-economic development of Nigeria.

Furthermore, predictions have been enacted about the possible upward surge in the contribution of GSM to the economy. Statista (2020) predicted that there would be $2.7 \%$ quarterly contribution by the Telecoms industry to GDP till 2021. Findings in this study agree with Statista's submission, therefore, it may be argued that with the advancement in technology devices, leverage of emerging innovation by youths and financial strategists, and an avalanche of opportunities arising daily that GSM could grow to become one of the two highest contributors to the GDP.

\section{References}

Adediran, O., Oduntan, E., \& Matthew, O. (2017). Financial Development and Inclusive Growth in Nigeria: A Multivariate Approach. Journal of Internet Banking and Commerce, 22(8), 1-14.

Adomi, E. A. (2006). Mobile phone usage: Patterns of library and information science. Electronic Journal of Academic and Special Librarianship, 7(1), 1-11.

Aigbinode, R. (2016). Seven years of telecoms revolution - the breathtaking revolution in telecoms industry. Tell Magazine of Nigeria, 25-28.

Ajayi, G. O. (2008). A Century of Telecommunications Development in Nigeria-What Next?

Ajiboye, O. J., Adu, O. E., \& Wojuaye, I. J. (2007). Stakeholders Perception of GSM on Nigeria Rural Economy: Implication for an Emerging Communication Industry. Journal of Information Technology, 7(2), 131-144.

Akinyomi, O. J., \& Tasie, C. (2015). Impact of telecommunication liberalization in Nigeria. A thesis submitted to the department of Financial Studies, Redeemer's University, Ogun State, Nigeria.

Aminu, A., \& Rafiu, I. (2019). ICT sector, output, and employment generation in Nigeria: Input-output approach. Munich Personal RePEc Archive, Germany.

Asogwa, F., Ohaleme, K., \& Ugwuanyi, O. (2013). The Impact of Telecommunications Expenditure on Economic Growth in Nigeria. Journal of Economics and Sustainable Development, 4(13).

Azubike, C., \& Obiefuna, O. (2014). Wireless Communication: The Impact of GSM on the Economic Lives of the Nigerian Rural Users. Journal of Educational and Social Research, 4(7). https://doi.org/10.5901/jesr.2014.v4n7p79

Bakare, A. S., Owusu, A., \& Abdurrahaman, D. T. (2017). The behavior response of the Nigerian youths toward mobile advertising: An examination of the influence of values, attitudes and culture. Cogent Business \& Management, 4(1). https://doi.org/10.1080/23311975.2017.1353231

Bakare, B. I., Ekanem, I., \& Allen, I. O. (2017). Appraisal of Global System for Mobile Communication (GSM) in Nigeria. American Journal of Engineering Research (AJER).

Bakare, S., \& Gold, K. (2017). Estimating the impacts of global system for mobile telecommunications (GSM) on income, employment, and transaction cost in Nigeria. Journal of Economics and International Finance, $3(1), 37-45$.

Chidozie, F., Odunayo, L., \& Ajayi, O. (2015). Deregulation of the Nigerian Telecommunication Sector: Interrogating the Nexus Between Imperialism and Development. Academic Journal of Interdisciplinary Studies. https://doi.org/10.5901/mjss.2015.v4n1p173

Durndell, A., \& Haag, Z. (2002). Computer self efficacy, computer anxiety, attitudes towards the Internet and reported experience with the Internet, by gender, in an East European sample. Computers in Human Behavior. https://doi.org/10.1016/S0747-5632(02)00006-7

Gold, K. L. (2011). Aggregate Analysis of the Impacts of Telecommunications Infrastructural development on Nigerian Economy. Proceedings of the 1st International Technology, Education and Environment Conference. African Society for Scientific Research (ASSR).

GSMA Intelligence. (2015). Digital inclusion and the role of mobile in Nigeria.

Ibukan, Y., \& Ackerman, G. (2019). Africa's technology hub rises in a congested Lagos neighbourhood.

Ige, O. (2012). Evolution of the telecommunications industry. Retrieved from 
http://www.ncc.gov.ng/archive/Archive\%20of\%20Speeches/telecomevolution-olawale_ige170402.pdf

International Post Corporation. (2017). Cross-border e-commerce shopper survey 2016. Brussels.

Internet World Stats. (2019). Retrieved from http://www.internetworldstats.com

ITU and CISCO. (2016). Harnessing the Internet of Things for Global Development. Geneva.

Iwayemi, A. (2017). The Elusive Quest for Adequate, Reliable and Affordable Electricity in Nigeria. Emerging Policy Issues and Agenda for Research, CPEEL Special Seminar Series 11, Thursday 10th Of August 2017.

Jackson, T. (2017). This Nigerian startup is taking care of your accounting.

Micah, D. H. (2014). Access to and utilization of global system for mobile telecommunications services among subscribers in Ibadan, Nigeria. A published PhD thesis submitted to the department of Sociology, University of Ibadan, Nigeria.

Micah, D. J. (2017). Access to and Utilization of Global Systems for Mobile Telecommunications Services Among Subscribers in Ibadan, Nigeria.

Mould, A. (2019). A Look at the GSM/Telecommunications Revolution in Nigeria.

NCC- National Communication Commission. (2017). Annual Report.

NCC- National Communication Commission. (2017). The role of the telecommunications sector in the diversification of the Nigerian economy-achievements, prospects, and challenge. Department of electrical engineering Bayero University, Kano.

Ndukwe, E. (2011). The Telecommunication Revolution in Nigeria. Text of the Convocation lecture delivered at the Igbinedion University Okada 2nd December 2011.

Nkordeh, N., Bob-Manuel, I., \& Olowononi, F. (2017). The Nigerian Telecommunications Industry: Analysis of the First Fifteen Years of the Growths and Challenges in the GSM. Proceedings of the World Congress on Engineering and Computer Science I WCECS 2017, October 25-27, 2017, San Francisco, USA.

Nwakanma, I. C., Asiegbu, B. C., \&Amadi, E. C. (2012). Quantitative Analysis of Factors Affecting Teledensity Growth in Nigeria. Microwave International Journal of Science and Technology, 3(1), 25-35.

Oxford Business Group. (2020). Telecoms growth in Nigeria supported by reforms and infrastructure.

Oyejide, A., \& Bankole, A. (2001). Liberalization of the Services Sector in Nigeria: Implications of Unilateral and Multilateral Approaches. A Paper Presented at the African Economic Research Consortium on Services Sector Liberalization in Nigeria.

Possible Applications in Nigeria's Electricity Industry. IAEE Energy Forum/Second Quarter 2019.

Statista. (2019). Nigeria telecom industry GDP contribution 2012-2019.

Statista. (2020). Global unique subscribers from 2010-2020, by region.

Suominen, K. (2017). Accelerating digital trade in Latin America and the Caribbean. Working paper, Inter-American Development Bank, Washington, DC. https://doi.org/10.18235/0000636

The Guardian Nigeria Publication. (2015). GSM and internet penetration in Nigeria. R

UNCTAD. (2017). UNCTAD E-Commerce Week 2017: Summary report.

UNCTAD. (2017). World Investment Report 2017: Investment and the Digital Economy. United Nations, New York, and Geneva.

Urama, N. E., \& Oduh, M. O. (2012). Impact of Developments in Telecommunications on Poverty in Nigeria. Journal of Economics and Sustainable Development, 3(6). https://doi.org/10.2139/ssrn.2171082

Wojuade, J. I. (2005). Impact of Global System for Mobile Telecommunication on Nigerian Economy: A Case of Some Selected Local Government Areas in Oyo State, Nigeria.

WorldPay. (2015). Your global guide to alternative payments 2015.

\section{Copyrights}

Copyright for this article is retained by the author(s), with first publication rights granted to the journal.

This is an open-access article distributed under the terms and conditions of the Creative Commons Attribution license (http://creativecommons.org/licenses/by/4.0/). 